\title{
Study on the Validity of Pancreaticoduodenectomy in the Elderly
}

\author{
YASURO FUTAGAWA, MASARU KANEHIRA, KENEI FURUKAWA, HIROAKI KITAMURA, \\ SEIYA YOSHIDA, TERUYUKI USUBA, TAKEYUKI MISAWA, YUICHI ISHIDA, \\ TOMOYOSHI OKAMOTO and KATSUHIKO YANAGA
}

Department of Surgery, The Jikei University School of Medicine, Tokyo, Japan

\begin{abstract}
Aim: Pancreaticoduodenectomy (PD) is still the only curative treatment for periampullary cancer. Confirming the outcomes of PD in elderly patients is important as the aging population continues to grow. Patients and Methods: We analyzed 340 patients with periampullary cancer who underwent $P D$, dividing them into three groups by age: group A: aged 64 years or younger, $n=115$; group B: 65-74 years, $n=144$; and group C: 75 years or older, $n=81$. Results: Group $C$ had a significantly higher 60-day mortality of 6.3\% $(p=0.04)$, the lowest 5-year overall survival rate of $9.9 \%$ $(p=0.02)$, and there was no impact of staging of the Union for International Cancer Control classification on overall survival of patients with pancreatic cancer. Independent prognostic factors of group $C$ in the multivariate analysis were pancreatic cancer and reoperation. Conclusion: For elderly patients aged 75 years or over, caution should be exercised in selecting $P D$ for patients with pancreatic cancer.
\end{abstract}

The elderly population aged 65 years and over is now increasing in developed countries. In 2014, there were 46 million people aged 65 years and over living in the United States alone, accounting for $15 \%$ of the total population. In 2030, the number of older Americans is expected to grow to 74 million, representing nearly $21 \%$ of the total U.S. population (1). In Japan, the number and proportion of the elderly people aged 65 years and over reached 34.6 million in 2016, accounting for the highest proportion of $27 \%$ (2). Advanced age of 60 years and over is noted as a risk factor for periampullary cancer; therefore, the number of elderly patients who require pancreaticoduodenectomy (PD) as a curative treatment is expected to further increase (3).

Correspondence to: Yasuro Futagawa, Department of Surgery, The Jikei University School of Medicine, 3-25-8 Nishishimbashi, Minato-ku, Tokyo 105-8461, Japan. Tel: +81 334331111, Fax: +81 354724140, e-mail: tiger@jikei.ac.jp

Key Words: Geriatric surgery, pancreaticoduodenectomy, survival.
The validity of performing PD for older patients remains controversial. Nowadays, the applicability of PD in elderly patients is determined on a case-to-case basis, considering various factors such as comorbidity, cancer staging, frailty, life expectancy, and postoperative quality of life. Although the evaluation of the grade of frailty for surgery remains to be established, approximately $20-30 \%$ of those over 75 years would be considered frail, and this figure tends to increase with age (4).

Knowing the surgical outcomes of PD in older patients is important to assist for decision making, because PD is still the only curative treatment for periampullary cancer, even in the elderly. This study aimed to confirm the validity of PD for elderly patients compared with their non-elderly counterparts.

\section{Patients and Methods}

This study was approved by the Institutional Review Board of the Jikei University School of Medicine in October, 2015. Among the 436 patients who underwent PD for various indications between January 2003 and December 2010 at four affiliated hospitals of the Jikei University School of Medicine, Tokyo, Japan, 340 patients with an operative indication of pancreatic cancer $(n=178)$, bile duct cancer $(n=96)$, or ampullary cancer $(n=66)$ were evaluated in this retrospective study. All four hospitals are currently certified by the Japanese Society of Hepato- Biliary-Pancreatic Surgery as highvolume centers. The patients who had a performance status of 3 or more, an American society of anesthesiologists (ASA) physical status of grade 5 or more, or dementia were considered as contraindicated for PD regardless of age. In our affiliated hospitals, consultation with each patient's cardiologist or pulmonologist for those with a medical history of cardiac or pulmonary disease is routinely performed to evaluate operability. The final decision for the indication of PD was made by the team conference with the attending surgeon, taking into consideration the consultants and anesthesiologists' evaluations, preoperative testing, and patient's performance status. None of the patients in this study received neoadjuvant chemotherapy or radiotherapy. The 340 patients were divided into three groups according to their chronological age: group $\mathrm{A}$, the non-elderly (aged 64 years or younger; $\mathrm{n}=115 ; 33.8 \%$ ); group $\mathrm{B}$, the early elderly (6574 years; $n=144 ; 42.3 \%$ ); and group $C$, the late elderly ( 75 years or older; $\mathrm{n}=81 ; 23.8 \%$ ). The patients' preoperative and intraoperative clinicopathologic characteristics are shown in Table I. 
Table I. Clinical characteristics of patients who underwent pancreaticodudenectomy by age.

\begin{tabular}{|c|c|c|c|c|}
\hline Factor & $\begin{array}{c}\text { Group A } \\
\text { Age }<65 \text { years }(\mathrm{n}=115)\end{array}$ & $\begin{array}{c}\text { Group B } \\
\text { Age }(65-74) \text { years }(n=144)\end{array}$ & $\begin{array}{c}\text { Group C } \\
\text { Age }(\geq 75) \text { years }(\mathrm{n}=81)\end{array}$ & $p$-Value \\
\hline \multicolumn{5}{|l|}{ Pre-operative } \\
\hline Age, years, median (IQR) & $58(53-61)$ & $70(67-72)$ & $77(76-79)$ & $<0.001$ \\
\hline Gender: male/female & $76 / 39$ & $89 / 55$ & $43 / 38$ & 0.18 \\
\hline Diabetes mellitus & $26(23.4 \%)$ & $40(28.4 \%)$ & $20(25.3 \%)$ & 0.68 \\
\hline Indication & & & & 0.94 \\
\hline Pancreatic cancer & $60(52.2 \%)$ & $75(52.1 \%)$ & $43(53.1 \%)$ & \\
\hline Bile duct cancer & $30(26.1 \%)$ & $43(29.9 \%)$ & $23(28.4 \%)$ & \\
\hline Ampullary cancer & $25(21.7 \%)$ & $26(18.1 \%)$ & $15(18.5 \%)$ & \\
\hline Stage & & & & 0.98 \\
\hline 0 & $1(0.9 \%)$ & $2(1.4 \%)$ & 0 & \\
\hline $\mathrm{IA}+\mathrm{IB}$ & $24(20.9 \%)$ & $35(24.3 \%)$ & $18(22.2 \%)$ & \\
\hline $\mathrm{IIA}+\mathrm{IIB}$ & $64(55.7 \%)$ & $81(56.3 \%)$ & $46(56.8 \%)$ & \\
\hline III & $26(22.6 \%)$ & $26(18.1 \%)$ & $17(21.0 \%)$ & \\
\hline Cholangitis & $18(15.9 \%)$ & $18(12.7 \%)$ & $13(16.5 \%)$ & 0.67 \\
\hline Total bilirubin $(\mathrm{mg} / \mathrm{dl}), \operatorname{mean} \pm \mathrm{SD}$ & $1.9 \pm 1.4$ & $2.3 \pm 2.4$ & $1.9 \pm 1.7$ & 0.21 \\
\hline \multicolumn{5}{|l|}{ Operative } \\
\hline Operative time (min), median (IQR) & $485(395-600)$ & $478(390-560)$ & $445(374-533)$ & 0.02 \\
\hline Blood loss (ml), median (IQR) & $1,040(335-4,280)$ & $950(240-3,500)$ & $940(318-2,410)$ & 0.12 \\
\hline Procedure, $\mathrm{n}(\%)$ & & & & 0.52 \\
\hline Classical Whipple & $59(51.3 \%)$ & $80(55.6 \%)$ & $48(59.3 \%)$ & \\
\hline SSPPD & $28(24.3 \%)$ & $25(17.4 \%)$ & $17(21.0 \%)$ & \\
\hline PPPD & $28(24.3 \%)$ & $39(27.1 \%)$ & $16(19.8 \%)$ & \\
\hline Concomitant portal vein resection (n, \%) & $9(7.8 \%)$ & $15(10.4 \%)$ & $1(1.2 \%)$ & 0.02 \\
\hline
\end{tabular}

IQR: Interquartile range; SD: standard deviation; PD: pancreaticoduodenectomy, i.e.; classical Whipple; SSPPD: substomach-preserving pancreaticoduodenectomy; PPPD: pylorus-preserving pancreatoduodenectomy.

Preoperative factors such as the indication for surgery, disease stage, and prevalence of diabetes mellitus were not significantly different among the three groups.

In terms of the operative factors, the median operative time was 445 minutes for group $\mathrm{C}$, which was shorter than that in the other two groups, and was significantly shorter than that for group A. Concomitant resection of the portal vein was significantly low in group $\mathrm{C}$ as compared to the other groups $(p=0.02)$.

Surgical procedures. All patients underwent laparotomy through a midline incision. Classic PD, subtotal stomach-preserving pancreaticoduodenectomy (SSPPD), or pylorus-preserving pancreaticoduodenectomy (PPPD) was performed after assessing resectability by excluding liver, peritoneal, or any other distant metastases. The extent of gastric resection (PD, SSPPD, or PPPD) was chosen according to the tumor extension or the preference of the attending surgeon. Reconstruction was conducted using a modified Child method. Basically, the pancreaticojejunostomy (PJ) procedure was performed in twolayer, end-to-side, duct-to-mucosa style with an external transabdominal pancreatic duct stent.

Definition of outcome measures. Postoperative pancreatic fistula (POPF) was defined according to the definitions proposed by the International Study Group on Pancreatic Fistulas (5). Delayed gastric emptying (DGE) was graded based on the International
Study Group of Pancreatic Surgery consensus definition (6). Perioperative mortality in the present study was defined as death within 60 days of PD. The overall survival was determined as the period from the date of the surgery until the end of follow-up or the date of death from any cause. For pathological staging, the Union for International Cancer Control (UICC) classification was utilized (7).

Assessments. The primary endpoint was to investigate the impact of age on short-term outcomes after PD, and the secondary endpoint was to evaluate long-term survival rates of the patients.

Statistical analysis. Results are presented as the mean \pm standard deviation or the median with interquartile ranges depending on data distribution. Continuous variables were compared between the study groups using the independent samples $t$-test or the Mann-Whitney $U$-test. Categorical data were compared using the chi-squared test and Fisher's exact test, as appropriate. Kaplan-Meier survival curve estimates and log-rank tests were used to compare survival rates. Significant prognostic factors depicted in the univariate analysis were entered into Cox proportional hazards analyses to determine the prognostic value for overall survival. Patients who died within 60 days of PD were excluded from analyses of prognostic factors. All $p$-values were two-sided, and a value of $p<0.05$ was considered significant. All analyses were performed using Stata Version 12.0 (StataCorp LP, College Station, TX, USA). 


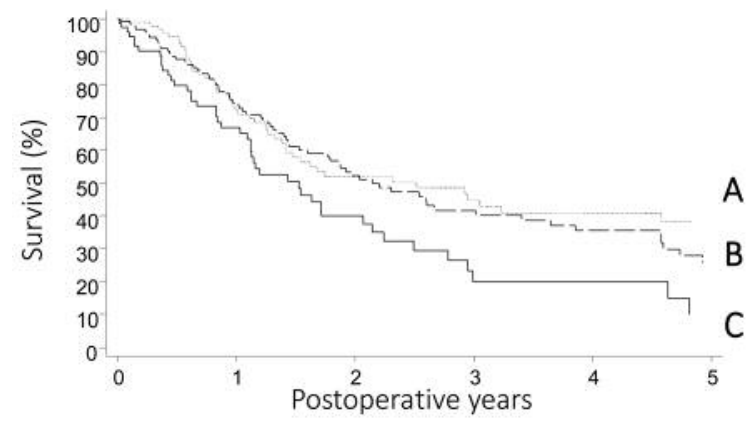

\begin{tabular}{lcc}
\hline & 5-year survival (\%) & Median survival (months) \\
\hline Group A $(n=115)$ & 38.3 & 30.6 \\
\hline Group B $(n=144)$ & 25.7 & 26.1 \\
Group C $(n=81)$ & 9.9 & 18.6 \\
\hline
\end{tabular}

Figure 1. Five-Year overall survival according to age group: Group A, the non-elderly (aged 64 years or younger); group B, the early elderly (65-74 years); and group $C$, the late elderly ( 75 years or older). The rate for group $C$ was the lowest and significantly lower than those for the other groups $(p<0.01$ compared with group $A ; p<0.02$ compared to group $B$.

\section{Results}

Perioperative outcomes. There were no differences in the median duration of postoperative hospital stay, the incidence of postoperative major complications such as POPF, DGE, and total intra-abdominal complications among the three groups (Table II). Groups B and C experienced significantly higher rates of reoperation than group A. Group $\mathrm{C}$ had the highest mortality rate of $6.3 \%(p=0.04)$. Among the five deaths in group $\mathrm{C}$, three were due to infection, such as pneumonia and catheter infection, whereas no infectionrelated death was observed in groups A and B.

Long-term survival. Group C yielded a significantly lower 5 -year overall survival as compared to the other two groups. The difference between group A and B was not significant (Figure 1). The 5-year cancer-specific survival rate of $16.7 \%$ in group $\mathrm{C}$ was the lowest, although there was no significant difference observed among the three groups (Figure 2).

Figure 3 shows the Kaplan-Meier curves for 5-year overall survival according to the pathological diagnosis for operative indication. For those with non-pancreatic cancer, the overall survival rate in group $\mathrm{C}$ was significantly lower than that in their counterparts (groups A and group B), with a median survival time of 25.2 months (Figure $3 \mathrm{a}$ ). For those with pancreatic cancer, the median survival time in group $\mathrm{C}$ was only 13.7 months; however, the survival rate of group $\mathrm{C}$ was not significantly lower than that of groups A and B (Figure 3b).

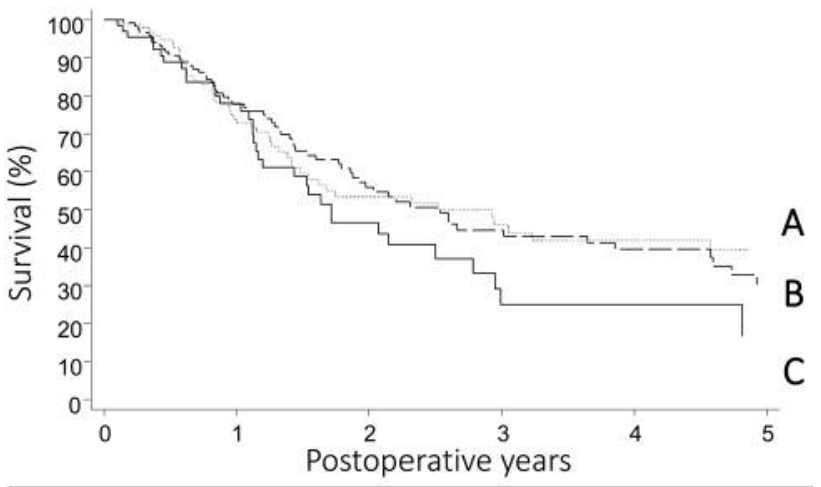

\begin{tabular}{lc}
\hline & 5-year cancer-specific survival (\%) \\
\hline Group A $(n=115)$ & 39.3 \\
Group B $(n=144)$ & 30.3 \\
Group C $(n=81)$ & 16.7 \\
\hline
\end{tabular}

Figure 2. Five-Year cancer-specific survival rate according to age group: Group A, the non-elderly (aged 64 years or younger); group B, the early elderly (65-74 years); and group $C$, the late elderly (75 years or older). The rate for group $C$ was the lowest although no significant difference was observed among the three groups ( $p=0.17 C$ compared with group $A ; p=0.12$ compared to group $B$ ).

Prognostic factors. Table III provides the results of univariate and multivariate analyses of prognostic factors for the three groups. In the univariate analysis, the diagnosis of pancreatic cancer, its stage, intraoperative blood loss, concomitant resection of the portal vein, and intraabdominal complications were identified as risk factors for poorer survival rate in group A or B. In group C, reoperation was identified as a risk factor in addition to the disease and its stage.

In the multivariate analysis, pancreatic cancer was noted as an independent prognostic factor in groups B and C. UICC stage was noted as an independent prognostic factor in groups $\mathrm{A}$ and $\mathrm{B}$ but not in group $\mathrm{C}$. Concomitant resection of the portal vein was noted as an independent prognostic factor in group A. Reoperation was noted as an independent prognostic factor in group C.

Figure 4 shows the Kaplan-Meier curves for 5-year overall survival of patients with pancreatic cancer according to the UICC stage in groups $\mathrm{A}$ and $\mathrm{B}$ versus group $\mathrm{C}$. In groups $\mathrm{A}$ and $\mathrm{B}$, a significant difference in survival rates by stage was observed (Figure 4a); however, in group $\mathrm{C}$, no difference in survival rates by stage was observed (Figure 4b). The median survival duration in groups $A$ and $B$ depended on disease stage. However, this trend was not noted for group $\mathrm{C}$ patients. 
a

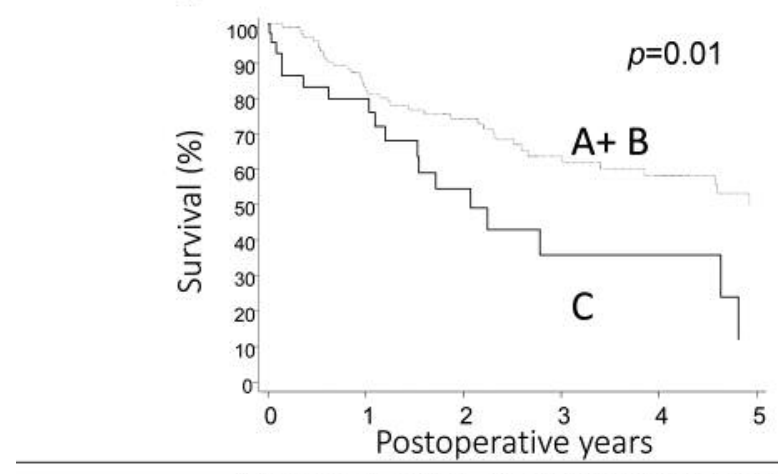

\begin{tabular}{ccc}
\hline & 5-year survival (\%) & Median survival (months) \\
\hline $\begin{array}{c}\text { Group } A+B \\
(n=124)\end{array}$ & 49.3 & 59.9 \\
$\begin{array}{c}\text { Group C } \\
(n=38)\end{array}$ & 11.8 & 25.2 \\
\hline
\end{tabular}

b

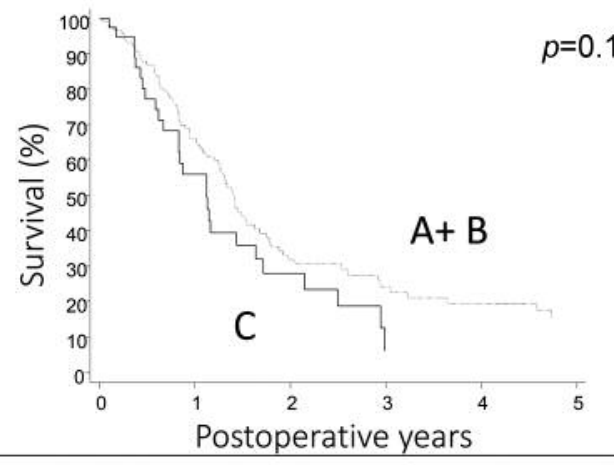

5-year survival (\%) Median survival (months)

\begin{tabular}{ccc}
$\begin{array}{c}\text { Group A + B } \\
(n=135)\end{array}$ & 15.6 & 17.0 \\
\hline $\begin{array}{c}\text { Group C } \\
(n=43)\end{array}$ & 6.2 & 13.7 \\
\hline
\end{tabular}

Figure 3. Five-Year overall survival according to the indication for surgery by age group: Group A, the non-elderly (aged 64 years or younger); group B, the early elderly (65-74 years); and group $C$, the late elderly (75 years or older). a: Non-pancreatic cancer. The survival rate for group $C$ (median survival time of 25.2 months) was significantly lower than that for groups $A$ and $B(p=0.01)$. $b$ : Pancreatic cancer. The median survival time for group $C$ was only 13.7 months, although the survival rate for group $C$ was not significantly lower than that of groups $A$ and $B(p=0.14)$.

\section{Discussion}

Previous studies in past fast two decades have compared the mortality and morbidity among younger and elderly patients who underwent PD (3, 8-11). In the majority of these studies, postoperative mortality and morbidity of older patients were slightly higher, but comparable to those of younger patients; however, the differences were significant in several large series $(3,8-11)$. In the present study, compared to patients younger than 75 years, patients aged 75 years and over had a significantly higher mortality rate, with half of the deaths being infection-related, such as pneumonia and sepsis due to catheter infection. Recently, a statistically significant increase in postoperative pneumonia in elderly patients (odds ratio in those aged 75 years or older as compared to their younger counterparts: 5.03 ; $95 \%$ confidence interval $(\mathrm{CI})=2.45-10.34$; $p<0.0001)(12)$ and postoperative pneumonia following PD as a high risk factor of mortality have been reported (13). Faraj et al. noted that septic shock has a significantly higher incidence $(6.5 \%)$ in patients over the age of 65 years, and was an independent risk factor for mortality (14). Aging of the immune system is observed because the capacity of the immune system to properly handle foreign microorganisms decreases with advanced age (15).

As to the significantly shorter operative time and the lowest rate of concomitant resection of the portal vein in group $\mathrm{C}$, shorter operative times in elderly groups has been reported in other series (16), that may be linked to the surgeon's willingness to shorten the operative time for the older patients considering that they are at greater risk. The lowest rate of concomitant resection of the portal vein being found in this group may also reflect cautious patient selection to avoid older patients with advanced pancreatic cancer because of their postoperative life expectancy (17).

To date, several studies have evaluated the long-term survival of elderly patients undergoing PD. Most of the studies showed a lower 5-year survival or shorter median survival in the elderly group, although the difference often did not reach significance, possibly because of small sample sizes $(3,8,18,19)$. One interpretation for the lower overall long-term survival of group $\mathrm{C}$ may be due to chronological age because there were no differences in cancer-specific survival between the three groups. However, there is still a possibility of lowered long-term survival due to cancerrelated death because there was a tendency for poorer cancer-specific survival of group $\mathrm{C}$ as compared to the other two groups. Elderly patients are expected to be less likely to tolerate chemotherapy and the drop-out rate will be higher. In fact, patients aged 75 years or over are reported to be less likely to be treated with adjuvant therapy (9). Lahat and colleagues reported that only $15 \%$ of patients aged 70 years and over who underwent PD for pancreatic cancer received chemotherapy as compared to $68 \%$ of patients aged 69 years and younger $(p=0.003)(19)$. 
a

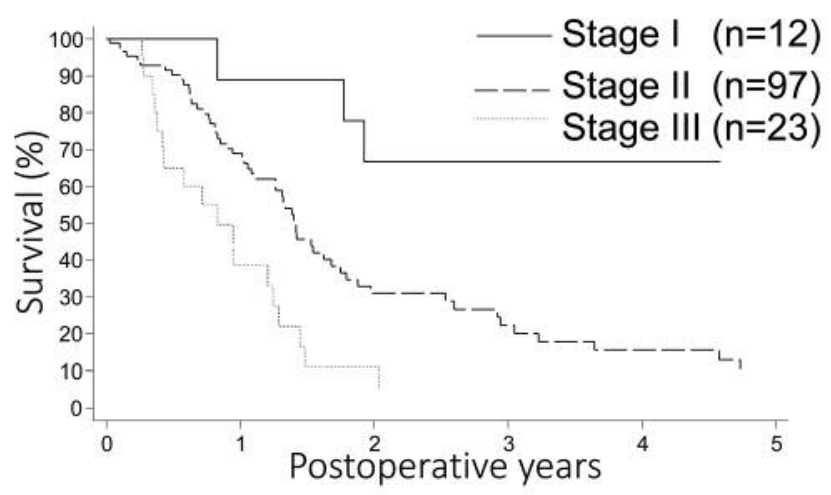

b

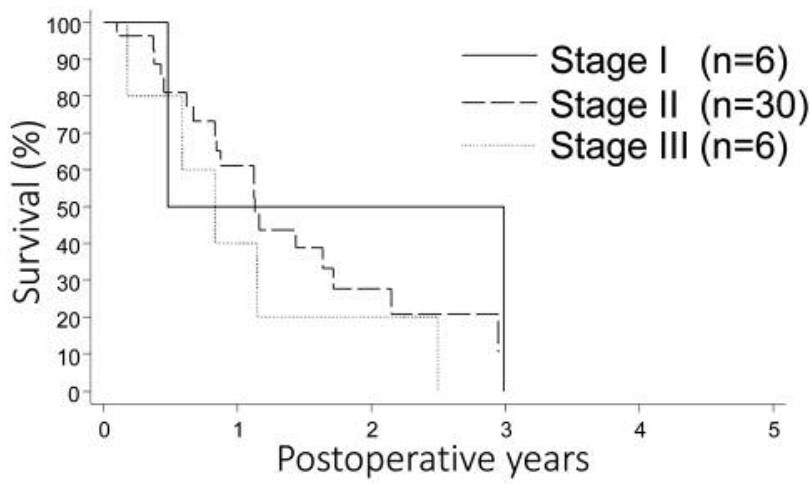

Median survival (months)

\begin{tabular}{cccc|} 
Stage & A+B & C & \\
\cline { 1 - 3 } I & $23.4^{*}$ & 5.8 & \\
II & 17.2 & 13.7 & $* 75 \%$ survival time \\
III & 10.1 & 10.1 & $*$
\end{tabular}

Figure 4. Five-Year overall survival rates of pancreatic cancer according to staging of the Union for International Cancer Control. a: Age $<75$ years. The differences in survival rates by stage were significant (stage I vs. II: $p=0.006$; stage II vs. III: $p=0.004$ ). $b$ : Age $\geq 75$ years. The differences in survival rates by stage were not significant (stage I vs. II: $p=0.38$; stage II vs. III: $p=0.29$; stage I vs. III: $p=0.38$ ).

Table II. Short-term outcomes by age.

Group A Group B Group C $\quad p$-Value

Factor Age $<65$ years $(n=115) \quad$ Age $(65-74)$ years $(n=144) \quad$ Age $(\geq 75)$ years $(n=81)$

Postoperative hospital stay (days),

median (interquartile range)

$26.5(22-35)$

$30(23-38)$

$30(25-38)$

0.36

Postoperative complication

POPF (grade B or C), n (\%)

$$
\begin{gathered}
18(15.7 \%) \\
24(20.9 \%) \\
4(3.5 \%) \\
12(10.4 \%) \\
6(5.2 \%) \\
25(21.7 \%)
\end{gathered}
$$

Bile leakage, n (\%)

Intra-abdominal abscess, $\mathrm{n}(\%)$

Intra-abdominal fluid collection, $\mathrm{n}(\%)$

Intra-abdominal complications*, n (\%)

Reoperation, n (\%)

0
$22(15.3 \%)$
$42(29.2 \%)$
$8(5.6 \%)$
$15(10.4 \%)$
$13(9.0 \%)$
$40(27.8 \%)$
$11(7.6 \%)$

$1(0.9 \%)$

Pseudoaneurysm rupture

Liver metastasis

\begin{tabular}{|c|c|c|c|}
\hline $1(0.9 \%)$ & $3(2.1 \%)$ & $5(6.3 \%)$ & 0.04 \\
\hline 0 & 1 & 1 & \\
\hline 1 & 0 & 1 & \\
\hline 0 & 1 & 0 & \\
\hline 0 & 1 & 0 & \\
\hline 0 & 0 & 2 & \\
\hline 0 & 0 & 1 & \\
\hline
\end{tabular}

Myocardial infarction

Bone marrow hypoplasia

Pneumonia

Catheter infection

POPF: Postoperative pancreatic fistula; DGE: delayed gastric emptying. *Intra-abdominal complications included pancreatic fistula, bile leakage, intra-abdominal abscess, intra-abdominal fluid collection, and intra-abdominal bleeding. 


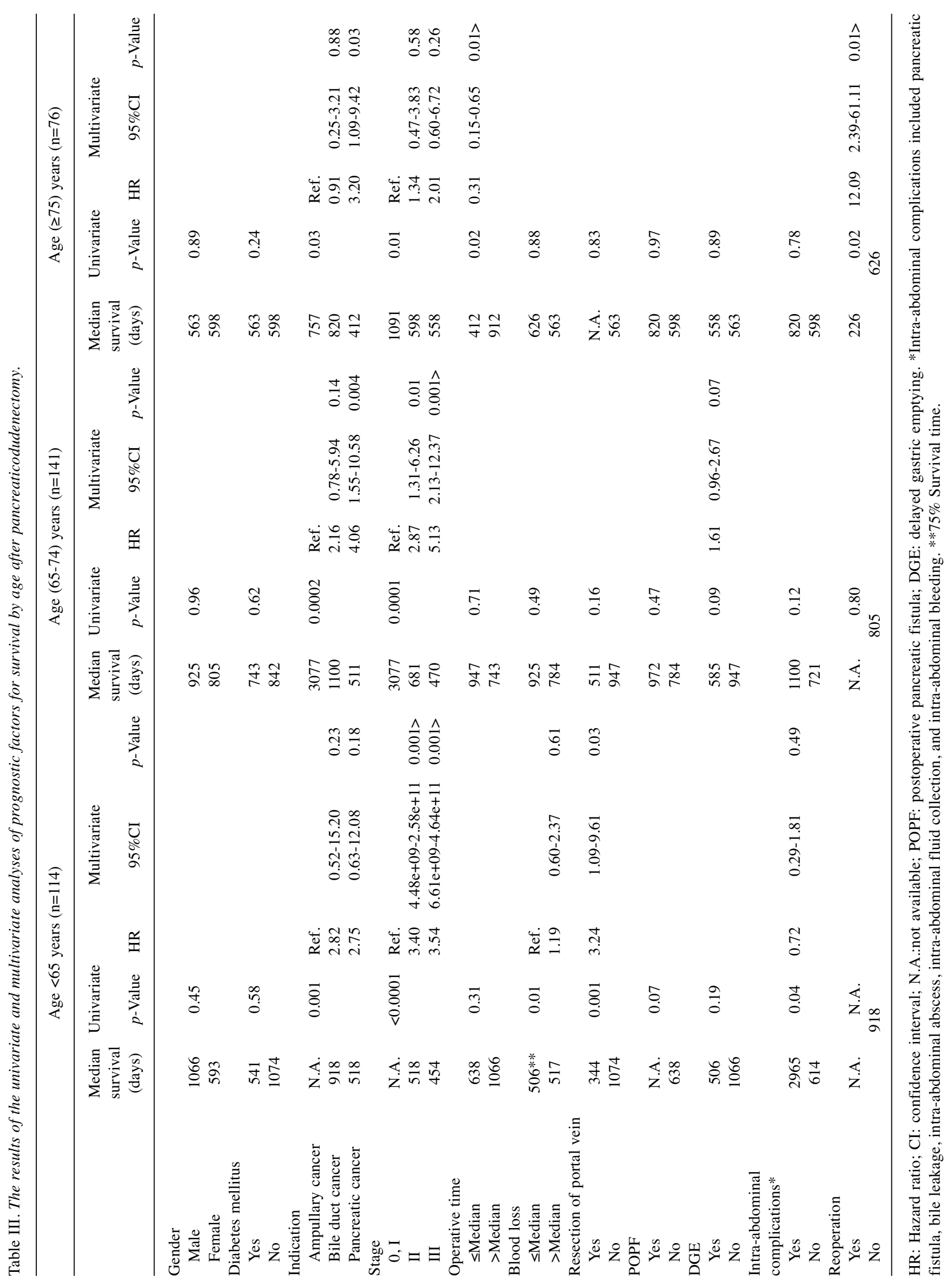


Recent studies have highlighted the clinicopathological factors influencing overall survival following PD, such as disease for PD indication, tumor size, lymph node metastases, and histological grade $(20,21)$. Among these factors, pancreatic cancer and UICC stage were highlighted in the present study. Regarding PD for non-pancreatic cancer, patients aged 75 years and over could have a relatively favorable long-term survival, while only non-elderly patients could yield a favorable long-term survival following PD for pancreatic cancer, but only in those with early-stage disease. The median survival for patients treated by radiochemotherapy alone was 8.9 months (22). Considering the impact of the disease, patients with pancreatic cancer should be separated from those with other types of cancers when considering PD. Another prognostic factor detected in the present study was cancer stage. In groups A and B, the effect of UICC stage on median survival for those with pancreatic cancer was obvious. On the other hand, in the patients aged 75 years and over, no impact of stage was found. With regard to pancreatic cancer in the elderly, the indication for PD, particularly in advanced cases, should be decided very carefully because additional chemotherapy is often not feasible (9). Particularly for those aged 75 years and over, performance of reoperation was the third prognostic factor in this study. A higher rate of reoperation in the elderly has been reported (23) and surgical complications that lead to reoperation are responsible for high mortality in elderly patients (10). Comorbidity, concomitant systemic disorders, reduced functional reserve, and subsequent poor tolerance to repeated surgical stress are the possible factors responsible for the high mortality rate after reoperation in elderly patients (24).

The limitations of the current study are its retrospective nature and the inability to evaluate frailty-related factors including comorbidities, such as cardiovascular diseases, ASA score, and preoperative nutritional status. These factors have been shown to affect patient outcome (22). Some patient data regarding adjuvant chemotherapy are also missing. Thereby, it was not possible to determine the contribution of cancer-related deaths to the lower overall survival.

\section{Conclusion}

We confirmed the validity of PD for bile duct cancer and ampullary cancer as a treatment option if appropriate preoperative evaluation and postoperative management are applied in elderly patients. Mortality associated with infectious diseases was high in patients over 75 years of age, and their long-term outcomes tended to be worse than those in the non-elderly. On the other hand, caution should be exercised for selection of PD in patients with pancreatic cancer, particularly in those with advanced stages.

\section{Conflicts of Interest}

The Authors have no conflicts of interest to declare.

\section{References}

1 Population Fact. Population Ageing and Sustainable Development. United Nations, Department of Economic and Social Affairs, Population Division. http://www.un.org./en/ development/esa/population/(accessed Jan. 2017).

2 Statistical Handbook of Japan 2016. Statistics Bureau Ministry of Internal Affairs and Communications Japan. Tokyo, Japan. http://www.stat.go.jp/english/data/handbook/index.htm (accessed Jan. 2017).

3 Riall TS: What is the effect of age on pancreatic resection? Adv Surg 43: 233-249, 2009.

4 Topinková E: Aging, disability and frailty. Ann Nutr Metab 52(Suppl 1): 6-11, 2008.

5 Bassi C, Dervenis C, Butturini G, Fingerhut A, Yeo C, Izbicki J, Neoptolemos J, Sarr M, Traverso W, Buchler M; International Study Group on Pancreatic Fistula Definition: Postoperative pancreatic fistula: an international study group (ISGPF) definition. Surgery 138(1): 8-13, 2005.

6 Wente MN, Bassi C, Dervenis C, Fingerhut A, Gouma DJ, Izbicki JR, Neoptolemos JP, Padbury RT, Sarr MG, Traverso LW, Yeo CJ and Büchler MW: Delayed gastric emptying (DGE) after pancreatic surgery: a suggested definition by the International Study Group of Pancreatic Surgery (ISGPS). Surgery 142(5): 761-768, 2007.

7 Sobin LH, Gospodarowicz MK and Wittekind Ch: TNM Classification of Malignant Tumors. Seventh Edition. Hoboken (United States): Wiley-Blackwell; 2010.

8 Makary MA, Winter JM, Cameron JL, Campbell KA, Chang D, Cunningham SC, Riall TS and Yeo CJ: Pancreaticoduodenectomy in the very elderly. J Gastrointest Surg 10(3): 347356, 2006.

9 Khan S, Sclabas G, Lombardo KR, Sarr MG, Nagorney D, Kendrick ML, Donohue JH, Que FG and Farnell MB: Pancreatoduodenectomy for ductal adenocarcinoma in the very elderly; Is it safe and justified? J Gastrointest Surg 14(11): 18261831, 2010.

10 Ballarin R, Spaggiari M, Di Benedetto F, Montalti R, Masetti M, De Ruvo N, Romano A, Guerrini GP, De Blasiis MG and Gerunda GE: Do not deny pancreatic resection to elderly patients. J Gastrointest Surg 13(2): 341-348, 2009.

11 Bergquist JR, Shubert CR, Ubl DS, Thiels CA, Kendrick ML, Truty MJ and Habermann EB: Risk by indication for pancreaticoduodenectomy in patients 80 years and older: a study from the American College of Surgeons National Surgical Quality Improvement Program. HPB 18(11): 900-907, 2016.

12 Sukharamwala P, Thoens J, Szuchmacher M, Smith J and DeVito $\mathrm{P}$ : Advanced age is a risk factor for post-operative complications and mortality after a pancreaticoduodenectomy: a meta-analysis and systematic review. HPB (Oxford) 14(10): 649-657, 2012.

13 Nagle RT, Leiby BE, Lavu H, Rosato EL, Yeo CJ and Winter JM: Pneumonia is associated with a high risk of mortality after pancreaticoduodenectomy. Surgery 161(4): 959-967, 2017.

14 Faraj W, Alameddine R, Mukherji D, Musallam K, Haydar A, Eloubiedi M, Shamseddine A, Halal A, Abou-Alfa GK, O'Reilly 
EM, Jamali F and Khalife M: Postoperative outcomes following pancreaticoduodenectomy: How should age affect clinical practice? World J Surg Oncol 11: 131, 2013.

15 Pawelec G, Solana R, Remarque E and Mariani E: Impact of aging on innate immunity. J Leukoc Biol 64(6): 703-712, 1998.

16 de Franco V, Frampas E, Wong M, Meurette G, Charvin M, Leborgne $J$ and Regenet N: Safety and feasibility of pancreaticoduodenectomy in the elderly: a matched study. Pancreas 40(6): 920-924, 2011.

17 Oguro S, Shimada K, Kishi Y, Nara S, Esaki M and Kosuge T: Perioperative and long-term outcomes after pancreaticoduodenectomy in elderly patients 80 years of age and older. Langenbecks Arch Surg 398(4): 531-538, 2013.

18 Oliveira-Cunha M, Malde DJ, Aldouri A, Morris-Stiff G, Menon KV and Smith AM: Results of pancreatic surgery in the elderly: Is age a barrier? HPB 15(1): 24-30, 2013.

19 Lahat G, Sever R, Lubezky N, Nachmany I, Gerstenhaber F, Ben-Haim M, Nakache R, Koriansky J and Klausner JM: Pancreatic cancer: surgery is a feasible therapeutic option for elderly patients. World J Surg Oncol 9: 10, 2011.

20 Liang DH, Shirkey BA, Rosenberg WR and Martinez S: Clinical outcomes of pancreaticoduodenectomy in octogenarians: a surgeon's experience from 2007 to 2015. J Gastrointest Oncol 7(4): 540-546, 2016.
21 Dasari BV, Roberts KJ, Hodson J, Stevens L, Smith AM, Hubscher SG, Isaac J, Muiesan P, Sutcliffe RP, Marudanayagam $\mathrm{R}$ and Mirza DF: A model to predict survival following pancreaticoduodenectomy for malignancy based on tumour site, stage and lymph node ratio. HPB 18(4): 332-338, 2016.

22 Pancreatric Section, British Society of Gastroenterology; Pancreatic Society of Great Britain and Ireland.; Association of Upper Gastrointestinal Surgeons of Great Britain and Ireland.; Royal College of Pathologists.; Special Interest Group for Gastro-Intestinal Radiology. Guidelines for the management of patients with pancreatic cancer periampullary and ampullary carcinomas. Gut 54(Suppl 5): v1-16, 2005.

23 DiCarlo V, Balzano G, Zerbi A and Villa E: Pancreatic cancer resection in elderly patients. Br J Surg 85(5): 607-610, 1998.

24 Aalami OO, Fang TD, Song HM and Nacamuli RP: Physiological features of aging persons. Arch Surg 138(10): 1068-1076, 2003.
Received July 10, 2017

Revised July 30, 2017

Accepted August 1, 2017 